\title{
Climatic changes in the Twenty-four Solar Terms during 1960-2008
}

\author{
QIAN Cheng ${ }^{1}$, YAN ZhongWei ${ }^{1 *} \&$ FU CongBin ${ }^{1,2}$ \\ ${ }^{1}$ Key Laboratory of Regional Climate-Environment for Temperate East Asia, Institute of Atmospheric Physics, Chinese Academy of Sciences, \\ Beijing 100029, China; \\ ${ }^{2}$ Institute for Climate and Global Change Research, School of Atmospheric Sciences, Nanjing University, Nanjing 210093, China
}

Received March 28, 2011; accepted July 11, 2011; published online September 12, 2011

\begin{abstract}
The temperature thresholds and timings of the 24 climatic Solar Terms in China are determined from a homogenized dataset of the surface air temperature recorded at 549 meteorological stations for the period 1960-2008 employing the ensemble empirical mode decomposition method. Changes in the mean temperature and timing of the climatic solar terms are illustrated. The results show that in terms of the mean situation over China, the number of cold days such as those of Slight Cold and Great Cold has decreased, especially by $56.8 \%$ for Great Cold in the last 10 years (1998-2007) compared with in the 1960s. The number of hot days like those of Great Heat has increased by $81.4 \%$ in the last 10 years compared with in the 1960s. The timings of the climatic Solar Terms during the warming period (around spring) in the seasonal cycle have advanced significantly by more than $6 \mathrm{~d}$, especially by $15 \mathrm{~d}$ for Rain Water, while those during the cooling period (around autumn) have delayed significantly by 5-6 d. These characteristics are mainly due to a warming shift of the whole seasonal cycle under global warming. However, the warming shift affects the different Solar Terms to various extents, more prominently in the spring than in the autumn. The warming tendencies for Rain Water, the Beginning of Spring, and the Waking of Insects are the largest, $2.43^{\circ} \mathrm{C}, 2.37^{\circ} \mathrm{C}$, and $2.21^{\circ} \mathrm{C}$, respectively, for the period 1961-2007 in China as a whole. Four particular phenology-related climatic Solar Terms, namely the Waking of Insects, Pure Brightness, Grain Full, and Grain in Ear, are found to have advanced almost everywhere. In semi-arid zones in northern China, advances of the timings of these four climatic Solar Terms are significant, 12-16, 4-8, 4-8, and 8-12 d, respectively, for the period 1961-2007. These quantitative results provide a scientific base for climate change adaptation, especially in terms of agricultural planning and energy-saving management throughout a year.
\end{abstract}

Twenty-four Solar Terms, climate change, ensemble empirical mode decomposition, human adaptation

Citation: Qian C, Yan Z W, Fu C B. Climatic changes in the Twenty-four Solar Terms during 1960-2008. Chin Sci Bull, 2012, 57: 276-286, doi: 10.1007/s11434011-4724-4

The Twenty-four Solar Terms are ancient Chinese terms that describe the 24 different timings (phases) in the seasonal cycle. They reflect not only seasonal sequences and transitions but also changes in phenology and crop growth. In particular, they are closely connected with agricultural activity in China, which is a large agricultural country. Peasant proverbs that summarize climate conditions in the Twenty-four Solar Terms have greatly contributed to agricultural development in China, and they still have considerable referential importance to modern agricultural activities. Ever since the birth of modern agrometeorology, the

*Corresponding author (email: yzw@tea.ac.cn)
Twenty-four Solar Terms have been combined with observational agrometeorological data in many places to compile the agricultural calendar and to plan agricultural activity. With time, the ancient experiences have been continuously adjusted using modern science and technology, and they continue to play an important role in guiding modern agricultural activity.

The Twenty-four Solar Terms originated from the ancient Yellow River Basin, which was a socioeconomic center. Back to the Spring and Autumn Period (770-476 BC), Chinese ancestors defined four important timings in a year: mid-spring, mid-summer, mid-autumn, and mid-winter. Through improvement over several centuries, the Twenty- 
four Solar Terms were fully documented in Tian Wen Xun, a chapter in the book Huai Nan Zi compiled in the early Han Dynasty. In 104 BC, during the Western Han Dynasty, the Twenty-four Solar Terms were laid down as a calendar in Tai Chu Li, the first calendar with complete written records in China. By then, the astronomical positions for the Twenty-four Solar Terms had been determined. The Twentyfour Solar Terms divide the ecliptic, which is the path that the Sun traces in the sky during the year and is measured in $360^{\circ}$ of longitude, into 24 equal segments, with two Solar Terms separated by $15^{\circ}$ of the Sun's longitude. Thus, there are two Solar Terms each month. At the Spring Equinox, the Sun's longitude is zero degrees. Such astronomical Twenty-four Solar Terms reflect the periodic change as the Earth orbits the Sun, and thus, the date in the Gregorian calendar of each Solar Term is almost fixed. For example, the Solar Terms in the first half year are mainly on the 6th or 21st day of the month in the Gregorian calendar, whereas those in the latter half year are mainly on the 8th or 23rd day. The date for each Solar Term varies only 1-2 d. However, a particular Solar Term is important to human activity in terms of the corresponding climate condition. This study investigates changes in the climate conditions of the Twenty-four Solar Terms under a changing climate in recent decades. Thus, it is necessary to properly define climatic Solar Terms.

The global mean temperature has increased by $0.74 \pm$ $0.18^{\circ} \mathrm{C}$ in the last 100 years (1906-2005) [1]. In the case of the Northern Hemisphere, many observational records have shown that the timing of "natural" spring (as opposed to the astronomical spring) has advanced several days in many places including China. For example, birds have been laying eggs, nesting, migrating, and arriving earlier than usual in recent years in Europe and North America [2,3]. Plants are blooming earlier and mammals are coming out of hibernation sooner than in previous decades [4-6]. Changes in ice breakup dates for lakes and rivers have also been reported [7]. There are many environmental phenomena therein. In addition, the climatic timing of the spring onset has also advanced [8,9]. As revealed from temperature records in China, increasing mean temperatures for all seasons [10], lengthening of the growing season [9,11-13], shortening of the frost season $[12,14]$, and advancing or delaying trends in the timings of the beginning or ending of seasons [9,15-17] have been well reported. How have the climatic Solar Terms changed under such a warming climate? This question has not yet been studied. It is expected that many peasant proverbs and experiences may need to be updated for the changing climate.

On the basis of a homogenized dataset of observations of surface air temperature (SAT), this study applies a recently developed time-series analysis method-ensemble empirical mode decomposition (EEMD) [18] — to investigate climatic changes of the Twenty-four Solar Terms. In particular, changes in the 24 climatic Solar Terms are reported to pro- vide a scientific base for human adaptation to climate change.

\section{Data and methods}

\subsection{SAT data}

The SAT data used in this study are updated homogenized daily mean temperature datasets for China from 1960 to 2008 based on recordings at 549 meteorological stations [19]. In these datasets, most of the unnatural local biases (e.g. biases due to relocations of meteorological stations and changes in observational protocols) have been adjusted [19]. Thus, these updated datasets are more suitable than the original datasets for large-scale climate-change analysis. The scheme for coping with the leap year is the same as that used by Qian et al. [20]: removing the value on 29 February and replacing the value on 28 February with the average value for 28 and 29 February. In this way, not only has the effect of the leap year been taken into account, but also the number of days in each year is always 365 , facilitating metric analysis.

\subsection{Brief introduction to EEMD}

EEMD [18] is applied to determine the 24 climatic Solar Terms (as opposed to the astronomical ones). EEMD, developed in recent years, is an adaptive and temporally local time series analysis method designed for analyzing nonlinear and nonstationary data, such as climate data. It decomposes any complicated data series into finite quasi-periodic components at different timescales. This decomposition is based on the data themselves, without introducing an a priori determined basis (such as trigonometric functions in Fourier analysis). Therefore, briefly speaking, it is an adaptive filter.

EEMD is a recent improvement of empirical mode decomposition (EMD) [21,22], in which the mode mixing problem of EMD is largely eliminated and the physical uniqueness of decomposition is preserved [18]. The procedures of the original EMD method are carried out through a so-called "sifting process" [21]: (1) fitting the local maxima (minima) of the input time series $X(t)$ with a cubic spline to form the upper (lower) envelope, and subtracting the local means of the upper and lower envelopes from the input time series to obtain a prototype of oscillation component $h_{1} ;$; 2 ) treating $h_{1}$ as the input and repeating step (1) as many times as is required until the first output oscillation component, called the intrinsic mode function (IMF) [21] is obtained; and (3) subtracting $\mathrm{IMF}_{1}$ from the input and repeating steps (1) and (2) to obtain $\mathrm{IMF}_{2}$. Likewise, $\mathrm{IMF}_{3}, \mathrm{IMF}_{4}, \cdots$ are obtained. Finally, the raw data are decomposed into finite IMFs and a trend. The principle underlying the EEMD method is to obtain the arithmetic mean of multiple observations, by adding multiple white noise realizations to the 
target data to mimic a scenario of multiple trials of observation for a single trial of observation. Through using an ensemble, EEMD cancels various realizations of white noise added to each trial of the ensemble and finally obtains scaleconsistent signals.

In recent years, EEMD has been applied by Chinese scholars in many climate-change research works, such as investigating the advancing trend in the timing of the climatic spring onset $[8,9]$, multi-timescale characteristics of temperature [23], trends in the weather/climate extremes [20], trends in the timings of the beginning and ending of seasons [17], and changes in the amplitude of the temperature annual cycle [24].

\subsection{Schemes for determining the thresholds of Solar Terms and for trend analysis}

Because of synoptic fluctuation in the raw daily temperature series, one often faces the difficulty that a given threshold has multiple intersections with the daily temperature, leading to multiple choices for the timing of interest in a year, which cannot be satisfactorily addressed by the running mean method [8,9]. In this study, the scheme proposed by Qian et al. [8], which is based on EEMD, is adopted to adaptively and uniquely determine the timings of the 24 climatic Solar Terms. The detailed procedures for the China mean series are as follows. (1) EEMD is applied to the China mean daily temperature series (the added white noise in each EEMD ensemble member has a standard deviation of 0.3 and the ensemble size is 1000) to filter out the highfrequency intra-annual timescale component and obtain the annual cycle and longer timescale component (ALC) [8], which is the sum of the EEMD components from the sixth to the last one (Figure 1(a)). To eliminate the minor influence of the end effect on our quantified result, the first and the last years [23] of the ALC series are excluded, leaving the period 1961-2007 to be analyzed. (2) The climatology of the ALC for the period 1961-1990 is calculated to form a smoothed 365-day series (Figure 1(b)), and the mean temperature for each solar term over the corresponding date range (Table 1) in this 365-day series is then taken as the threshold (Figure 1(b); Table 1). For example, the Beginning of Spring is always during 3-5 February. Thus, the mean temperature of the climatological ALC over these three days is taken as the threshold for the Beginning of Spring. The date when the ALC series intersects with the threshold of each Solar Term (except Great Cold, Slight Cold, the Beginning of Spring, the Winter Solstice, Slight Heat, the Beginning of Autumn, and Great Heat) (Figure 2) for the first (second) time each year is determined as the
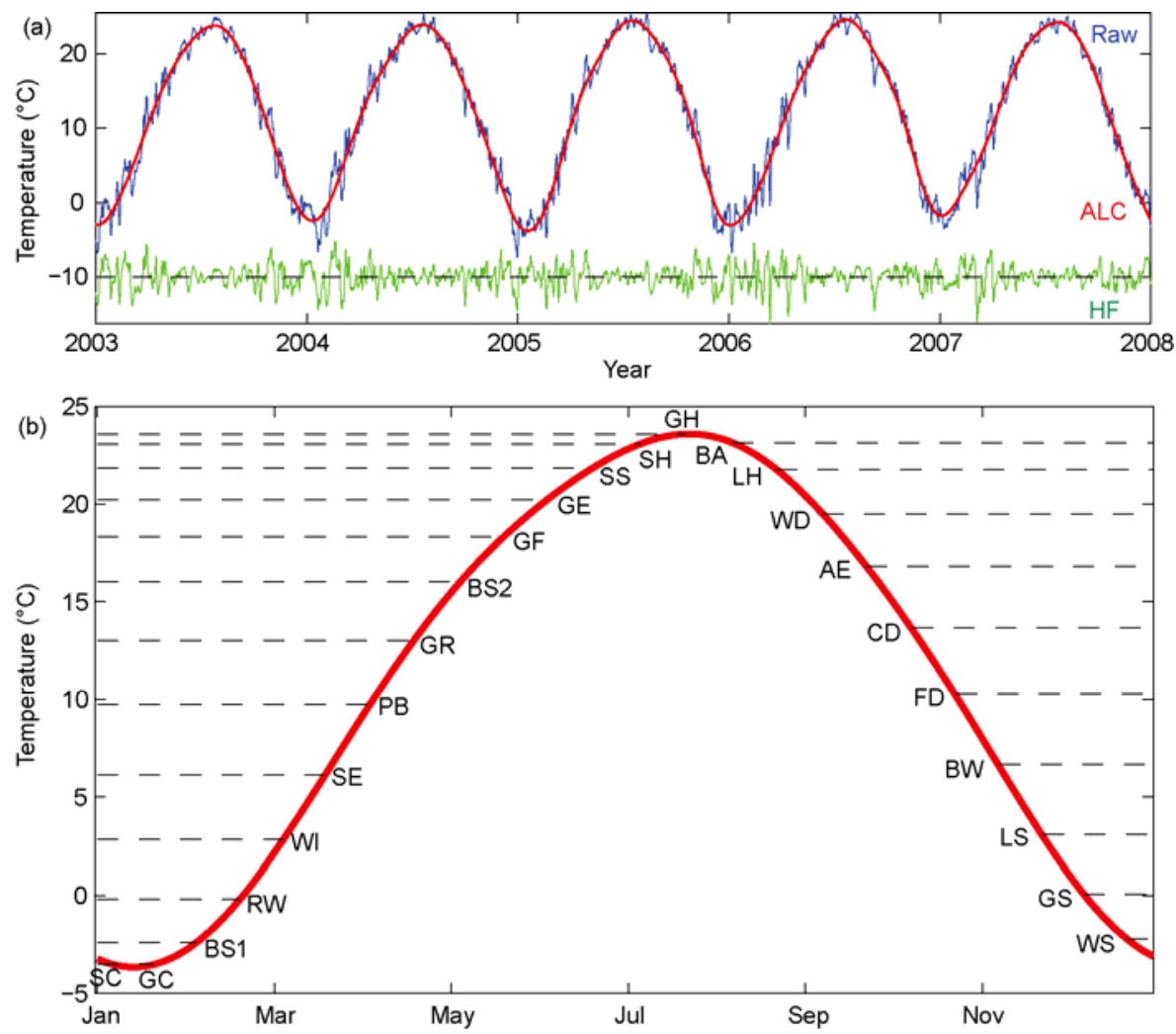

Figure 1 Schematic diagram for determining the 24 Solar Terms and their corresponding thresholds of the China mean temperature. (a) Diagram of smoothing (i.e. filtering out high-frequency fluctuations ("HF", in green)) raw daily SAT series ("Raw", in blue) to obtain an annual cycle and longer timescale component ("ALC", in red) employing EEMD. In the magnified view, only the last five years (2003-2007) have been shown. (b) Climatological mean ALC for the period 1961-1990 (solid line). Dashed lines indicate the threshold for each Solar Term, which is given in abbreviation and listed in Table 1. 
Table 1 Trends in the China mean temperature for the 24 climatic Solar Terms from 1961 to 2007

\begin{tabular}{|c|c|c|c|c|}
\hline Solar Terms & Date & Threshold $\left({ }^{\circ} \mathrm{C}\right)$ & Advancing trend ${ }^{\text {a) }}(\mathrm{d} / 47 \mathrm{a})$ & Warming trend $\left({ }^{\circ} \mathrm{C} / 47 \mathrm{a}\right)$ \\
\hline The Beginning of Spring (BS1) & February $3-5$ & -2.40 & - & $2.37(0.01)$ \\
\hline Rain Water (RW) & February $18-20$ & -0.20 & $14.6(0.01)$ & $2.43(0.01)$ \\
\hline The Waking of Insects (WI) & March 5-7 & 2.84 & $11.0(0.01)$ & $2.21(0.01)$ \\
\hline The Spring Equinox (SE) & March 20-21 & 6.14 & $8.8(0.01)$ & $1.25(0.01)$ \\
\hline Pure Brightness (PB) & April 4-6 & 9.76 & $7.2(0.01)$ & $1.52(0.01)$ \\
\hline The Beginning of Summer (BS2) & May 5-7 & 16.02 & $6.2(0.01)$ & $1.02(0.01)$ \\
\hline Grain Full (GF) & May $20-22$ & 18.33 & $6.8(0.01)$ & $0.95(0.01)$ \\
\hline Grain in Ear (GE) & June $5-7$ & 20.23 & $8.0(0.01)$ & $0.96(0.01)$ \\
\hline The Summer Solstice (SS) & June $21-22$ & 21.83 & $9.7(0.01)$ & $0.63(0.01)$ \\
\hline Slight Heat (SH) & July 6-8 & 23.08 & - & $0.80(0.01)$ \\
\hline Great Heat $(\mathrm{GH})$ & July $22-24$ & 23.59 & - & $0.62(0.05)$ \\
\hline The Limit of Heat (LH) & August 22-24 & 21.78 & $-5.0(0.01)$ & $0.61(0.01)$ \\
\hline White Dew (WD) & September 7-9 & 19.50 & $-5.5(0.01)$ & $0.85(0.01)$ \\
\hline The Autumnal Equinox (AE) & September 22-24 & 16.83 & $-6.1(0.01)$ & $1.09(0.01)$ \\
\hline Cold Dew (CD) & October 8-9 & 13.67 & $-6.0(0.01)$ & $0.81(0.01)$ \\
\hline Frost's Decent (FD) & October $23-24$ & 10.28 & $-4.5(0.01)$ & $0.83(0.01)$ \\
\hline The Beginning of Winter (BW) & November $7-8$ & 6.66 & $-5.0(0.01)$ & $0.83(0.01)$ \\
\hline Light Snow (LS) & November $22-23$ & 3.09 & $-5.2(0.01)$ & $0.85(0.01)$ \\
\hline Great Snow (GS) & December 6-8 & 0.08 & $-6.5(0.01)$ & $1.35(0.01)$ \\
\hline The Winter Solstice (WS) & December 21-23 & -2.23 & - & $1.46(0.01)$ \\
\hline Slight Cold (SC) & January 5-7 & -3.50 & - & $1.77(0.01)$ \\
\hline Great Cold (GC) & January $20-21$ & -3.51 & - & $1.39(0.01)$ \\
\hline
\end{tabular}

a) Positive signs indicate advancing trends whereas negative signs indicate delaying trends; significance levels are given in parentheses.

timing of each climatic Solar Term in the first (second) half of the year. For convenience, these timings are arranged by their date order in a year (Figure 3). Linear trends in these timings are then estimated and their significances are assessed employing the Mann-Kendall test (Table 1). Since there are occasions when the ALC series does not intersect with the threshold for seven Solar Terms (i.e. Great Cold, Slight Cold, the Beginning of Spring, the Winter Solstice, Slight Heat, the Beginning of Autumn, and Great Heat) (Figure 2), trends in the timings of these seven Solar Terms are not investigated. In addition to the timings, trends in the mean temperatures of the Twenty-four Solar Terms for China are also estimated and their statistical significances are assessed employing the Mann-Kendall test (Table 1). These mean temperatures are the average temperatures in the ALC series over the date range of each Solar Term each year. For example, the mean temperature of the aforementioned the Beginning of Spring each year is the ALC averaged over 3-5 February each year.

Besides the mean situation for China, the geographic distributions of the trends in the timing of four particular phenology-related Solar Terms, namely the Waking of Insects, Pure Brightness, Grain Full, and Grain in Ear, are investigated separately. To determine local changes, the concept of the local threshold used by Yan et al. [17] is adopted to determine the thresholds of these four Solar Terms for each station according to the seasonal cycle of each station. The procedures are as follows. (1) EEMD is applied to the daily temperature series of each station to obtain the ALC series for the period 1961-2007. This step is similar to the aforementioned step (1) for the China mean series. (2) The climatological mean ALC for the period 1961-1990 is calculated for each station to obtain a 365-day series, which is considered the usual climate condition. (3) The mean temperature of this 365-day series over the date range of each of the four particular Solar Terms is taken as the corresponding threshold. In this way, an advancing (delaying) trend in the timings of the four Solar Terms at each station indicates that the timings occur earlier (later) than usual.

\section{Analysis}

In terms of the basic characteristics of the Twenty-four Solar Terms of the mean situation over China (Figure 1(b); Table 1), the coldest solar term is Great Cold $\left(-3.51^{\circ} \mathrm{C}\right)$ and the hottest is Great Heat $\left(23.59^{\circ} \mathrm{C}\right)$. These two seasonal extremes are the same under current global warming as they 

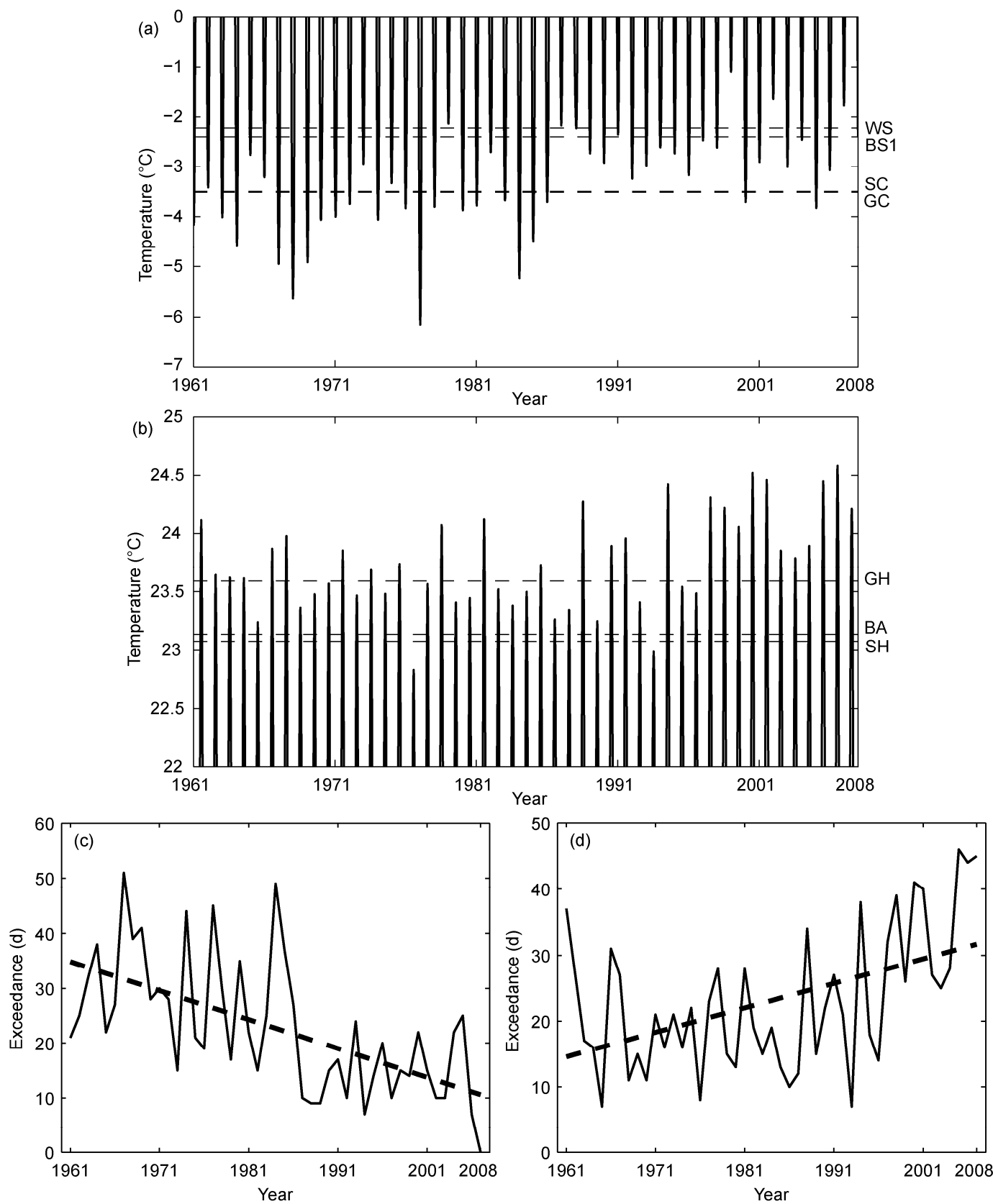

Figure 2 The coldest (a) and hottest (b) periods in the smoothed China mean daily temperature series (solid line, which is the ALC in Figure 1(a)) for the period 1961-2007. Dashed lines indicate the temperature threshold for each Solar Term, which is given in abbreviation and listed in Table 1. (c) and (d) are the annual occurrence of Great Cold and Great Hot, respectively. Dashed lines indicate linear trends.

used to be 2000 years ago, when they were summarized according to experience by ancient Chinese peasants. The Beginning of Spring $\left(-2.40^{\circ} \mathrm{C}\right)$ is the first Solar Term and literally means the beginning of the spring season. However, in terms of the mean situation over China in recent decades, the temperature during this solar term is still below $0^{\circ} \mathrm{C}$. During the Waking of Insects $\left(2.84^{\circ} \mathrm{C}\right)$, insects, feeling the warming weather, start to come out of hibernation underground. At this time, the weather warms, the soil melts, and plants start to green, all of which provide a breath of spring. There is also a peasant proverb indicating spring sowing begins after the Waking of Insects. At the time of the Spring Equinox $\left(6.14^{\circ} \mathrm{C}\right)$, peasants have been urged to do farm work. Therefore, from a phenological perspective, it is more practical for the Waking of Insects rather than other Solar Terms to serve as the timing of the spring onset. Currently, $10^{\circ} \mathrm{C}$, which was proposed by Zhang et al. [25], is widely used by meteorological services as the threshold for the timing of the spring onset. In terms of the China mean, this threshold is observed after Pure Brightness $\left(9.76^{\circ} \mathrm{C}\right)$, when plants have already flourished. In this sense, $5^{\circ} \mathrm{C}$, which is observed between the Waking of Insects and the Spring 
Equinox, may be more suitable than $10^{\circ} \mathrm{C}$ as the temperature threshold for the timing of the spring onset. The Summer Solstice $\left(21.83^{\circ} \mathrm{C}\right)$ is a transition Solar Term in both astronomy and meteorology. Thus, the currently used $22^{\circ} \mathrm{C}$ threshold for the timings of the transitions from spring to summer and from summer to autumn suits the mean situation over China, and the two months between the Summer Solstice and the Limit of Heat $\left(21.78^{\circ} \mathrm{C}\right)$ are the summer season. After the Limit of Heat, the temperature decreases gradually and drops below $5^{\circ} \mathrm{C}$ after the Beginning of Winter $\left(6.66^{\circ} \mathrm{C}\right)$. Thus, $5^{\circ} \mathrm{C}$ is also a suitable threshold for the timing of transition from autumn to winter. After Great Snow, the temperature drops below $0^{\circ} \mathrm{C}$ and the Winter Solstice $\left(-2.23^{\circ} \mathrm{C}\right)$ follows. Although the solar radiation gained by the earth is the least since the daytime is the shortest during the Winter Solstice, it is not the coldest time of the year owing to the energy stored by the earth during summer and autumn. By the time of the Great Cold, this energy is used up, resulting in the coldest period.

The above are statistically usual conditions. However, under the current warming climate, the statistics for the Twenty-four Solar Terms vary. Figure 2 shows that in terms of the China mean, the coldest episode (below $0^{\circ} \mathrm{C}$ ) of the seasonal cycle has been warming gradually as a whole. When the base period 1961-1990 is viewed as usual, severely cold days like those of Slight Cold and Great Cold have seldom been observed since 1987, and the number of cold days like those of the Beginning of Spring and the Winter Solstice has also decreased since the late 1990s. Meanwhile, the warmest episode (above $22^{\circ} \mathrm{C}$ ) of the seasonal cycle has been warming prominently on the whole since 1997, with there having been 11 consecutive years with severely hot days like those of Great Heat. Before 1994, there were years no hotter than the thresholds of Slight Heat and the Beginning of Autumn; however, thereafter, 14 consecutive years met these thresholds. The annual occurrence of cold days like those of Great Cold has decreased significantly (Figure 2(c)), by $56.8 \%$ in the last 10 years (hereafter referring to the period 1998-2007) (14.0 d/a) relative to the number in the 1960s (32.4 d/a). In 2007, all days were above the threshold temperature of Great Cold. On the other hand, the annual occurrence of hot days like those of Great Heat has increased significantly (Figure 2(d)), by $81.4 \%$ over the last 10 years $(36.1 \mathrm{~d} / \mathrm{a})$ relative to the occurrence in the 1960s (20.0 d/a). Figure 3(a) shows that all the analyzed climatic Solar Terms in the warming period of the seasonal cycle have both prominent interannual variations and significant (Table 1) advancing trends, with all advancing trends being greater than $6 \mathrm{~d}$ for the period 1961-2007. In particular, the advancing trends for Rain Water, the Waking of Insects, and the Summer Solstice are the largest, being $14.6 \mathrm{~d}$ (corresponding to half a month earlier than usual in the timing of meeting the threshold of Rain Water), $11.0 \mathrm{~d}$, and $9.7 \mathrm{~d}$, respectively. If $5^{\circ} \mathrm{C}$, which is widely used as the threshold for the start of the growing season at mid- to high latitudes home and abroad [8,9,12,13, 26 , is used as the threshold for the timing of the spring onset, this timing has advanced by $9.5 \mathrm{~d}$ for the period 1961-2007 (figure not shown). In contrast, all the analyzed climatic Solar Terms in the cooling period of the seasonal cycle have delayed significantly (Figure 3(b); Table 1) by about 5-6 d.



Figure 3 Trends (dashed lines) in the timing (solid lines) of the China mean in climatic Solar Terms for the period 1961-2007. (a) The warming period and (b) the cooling period of the season cycle. In (a) and (b), the abbraviations denote Solar Terms, which are listed in Table 1. 
The previous analysis on changes in the climatic Solar Terms suggests that there is a tendency of a warming shift of the whole seasonal cycle of the China mean, which is supported by the results (Table 1) of analyzing the trends in the mean temperature of each Solar Term. It is seen that the warming trends for the different Solar Terms vary from $0.5^{\circ} \mathrm{C}$ to $2.43^{\circ} \mathrm{C}$ per 47 years in the period $1961-2007$, and all trends are significant at $P<0.01$ except that of Great Heat at $P<0.05$. The warming trend of Rain Water is the largest, which is consistent with aforementioned findings that the advancing trend in this Solar Term is the largest. In addition, the Beginning of Spring, Rain Water, and the Waking of Insects all have warmed by more than $2^{\circ} \mathrm{C}$, which is much more than the case for Great Cold $\left(1.39^{\circ} \mathrm{C}\right)$. A possible reason for this discrepancy is that the mean temperatures for the former three Solar Terms are all around $0^{\circ} \mathrm{C}$, which is the melting temperature of ice and snow. The melting during the cold season on the Eurasian continent accelerates under global warming, reducing surface albedo and thus allowing more absorption of heat that would otherwise be reflected. In this way, the land surface warms more quickly during the former three Solar Terms than during Great Cold. In contrast, the temperature in Great Cold is always below $0^{\circ} \mathrm{C}$, without the positive feedback between ice-snow melting and warming. On the other hand, the weakening East Asian winter monsoon during the late winter and early spring [9] may also have played a role in the larger warming trends of the Beginning of Spring, Rain Water, and the Waking of Insects. Another distinct feature is that the warming trends are more prominent in the warming period of the seasonal cycle than in the cooling period, which is also consistent with the aforementioned findings that the advancing trends in the former are generally larger than the delaying trends in the latter. This discrepancy may be also due to the lack of positive feedback between ice-snow melting and warming. In addition, the comparison between the mean ALC for the last 10 years and that for the first 10 years (Figure 4) supports the tendency of a warming shift of the whole seasonal cycle in recent decades. It can be further inferred from this comparison that the Beginning of Spring, Slight Heat, and Great Heat are advancing, that the Beginning of Autumn and the Winter Solstice are delaying, and that Slight Cold and Great Cold are disappearing. In summary, the advancing and delaying trends of the Solar Terms are due to the warming shift of the whole seasonal cycle.

The geographic distribution patterns (Figure 5) show that the four phenology-related climatic Solar Terms have advanced throughout almost all of China in recent decades, with the advancing trend in the Waking of Insects being the most prominent. The local timing of the Waking of Insects (Figure 5(a)) has advanced at all stations, with the largest trends (16-20 d/47 a) seen in Beijing, Tianjin, and some stations nearby, and in western Yunnan. Trends are significant at all stations north of $33^{\circ} \mathrm{N}$ and more prominent in the east than in the west. These characteristics are consistent with the results obtained from analyzing the trends in the timing of the spring onset in northern China by Qian et al. [9], who suggested that the weakening East Asian winter monsoon has led to advancing trends being more prominent in the east than in the west, since both east and west are affected by global warming whereas the east is more directly affected by the East Asian winter monsoon. In central China south of $33^{\circ} \mathrm{N}$, especially at sites near the Sichuan Basin and in eastern Yunnan, the advancing trends are not statistically significant and are almost the smallest in China. Warming trends in these areas have not been significant in the last 50 years and some sites have even had a cooling

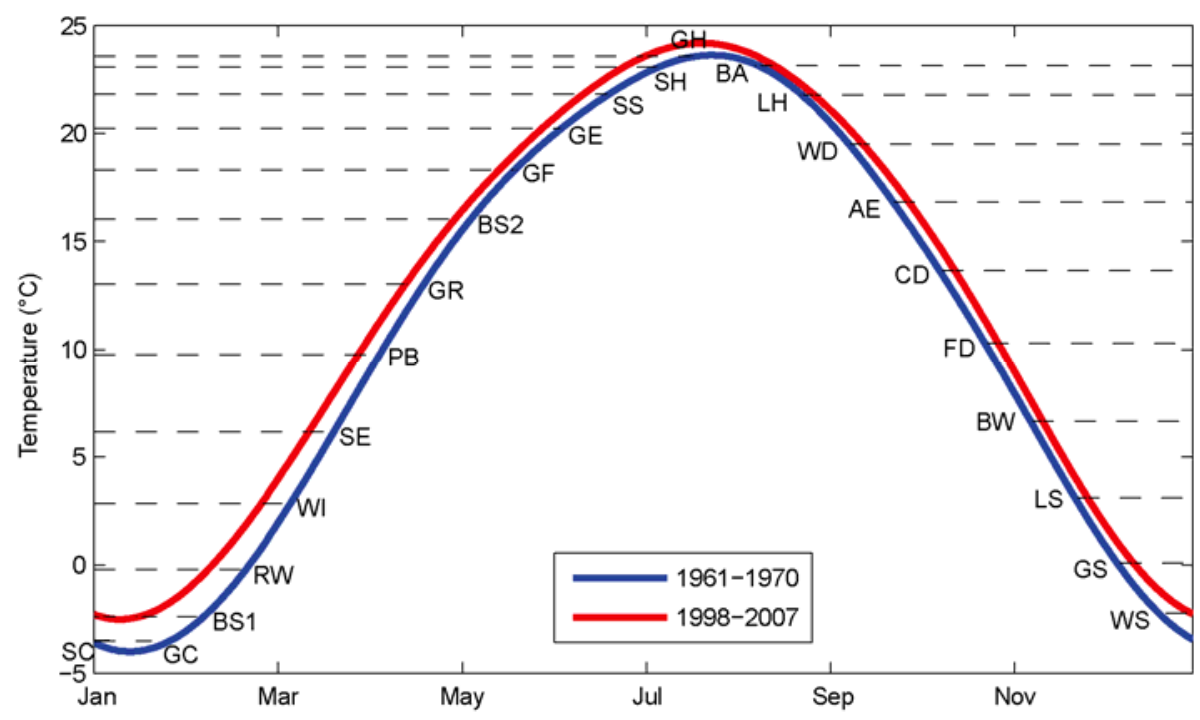

Figure 4 Climatological mean ALCs (seasonal cycles) of the China mean temperature for the earliest 10 years (blue line) and for the latest 10 years (red line). Dashed lines indicate the temperature thresholds for the 24 Solar Terms, which are listed in Table 1 and are the same as in Figure 1 . The abbreviations denote Solar Terms, which are listed in Table 1. 

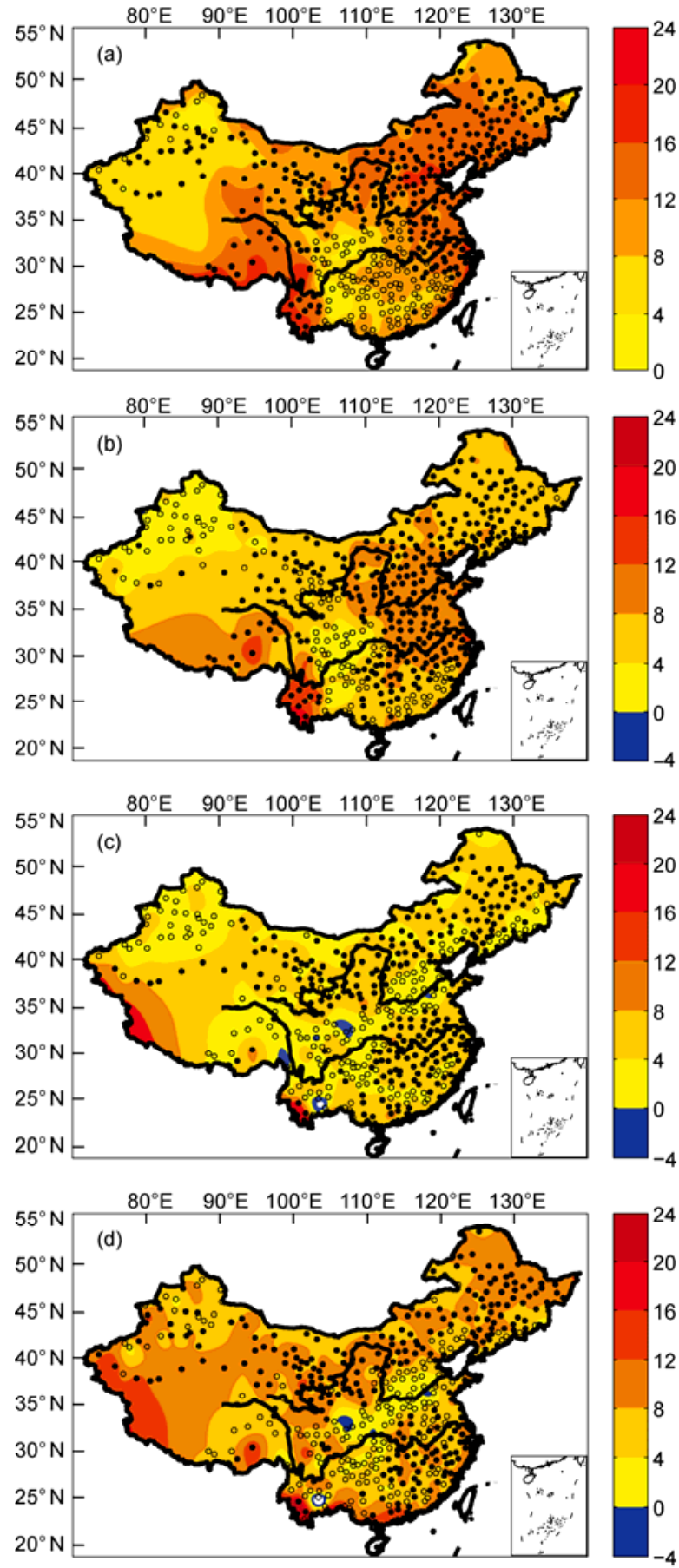

Figure 5 Geographic distributions of trends in the four phenology-related climatic Solar Terms for the period 1961-2007. (a) is for the Waking of Insects, (b) is for Pure Brightness, (c) is for Grain Full, and (d) is for Grain in Ear. In all panels, a warm color indicates an advancing trend whereas a cold color indicates a delaying trend. A dot indicates the linear trend is statistically significant $(P<0.05)$, whereas a circle indicates statistical insignificance. Units in all color bars are $\mathrm{d} / 47 \mathrm{a}$.

tendency, although not significant ones [19]. Li et al. [27] suggested that cloud-climate feedback processes could play a significant role in the amplification of the early spring cooling shift downstream of the Tibetan Plateau. In contrast, on the southeastern Tibetan Plateau, the timing of the Wak- ing of Insects has advanced significantly, which is consistent with the significant warming trends in this area during spring (figure not shown). This result reflects the seasonal climate change under global warming. Pure Brightness has advanced at all stations except Langzhong in Sichuan, and the advances have been statistically significant everywhere except in northwestern Xinjiang, Sichuan, eastern Yunnan, and some southeastern coastal areas. The largest advancing trend was in western Yunnan (about 12-20 d), and the second largest (about 8-12 d) was on the North China Plain, in most parts of the Yangtze-Huaihe Basin, and on the southeastern Tibetan Plateau. In Sichuan and Yunan and on the southeastern Tibetan Plateau, trends were similar to those for the Waking of Insects. Grain Full has advanced at all stations except several stations in Yunnan, Sichuan, and Shandong, with advances being significant in southwestern Yunnan (12-16 d), semiarid zones in northern China (4-8 d), the Yangtze-Huaihe Basin (4-8 d), and southeastern coastal areas (4-8 d). Grain Full and Grain in Ear are only separated by about 15 days, and the geographic distribution of the trends in the timing of the latter is thus very similar to that of the former. However, the trends are larger for the former than for the latter, such as in the semiarid zones in northern China and in the Yangtze-Huaihe $\operatorname{Basin}(8-12 \mathrm{~d})$.

\section{Discussion}

In terms of the timings of season beginnings, the present results agree with previous studies in many ways if the Beginning of Spring, the Beginning of Summer, the Beginning of Autumn, and the Beginning of Winter are considered as the timings of transitions between seasons, or if $5^{\circ} \mathrm{C}$ is used as the threshold temperature for winter/spring and autumn/winter transitions and $22^{\circ} \mathrm{C}$ is used as the threshold temperature for spring/summer and summer/autumn transitions. For example, the present study agrees with the finding of Dong et al. [15], Ye et al. [16], and Yan et al. [17] that trends in the timing of season beginnings, for the mean situation over China, are an earlier onset of spring and summer and a later onset of autumn and winter, resulting in lengthening of the summer season and shortening of the winter season. Another agreement is that the advancing trend in the timing of the spring onset is larger than the delaying trend in the timing of the autumn onset. However, when $5^{\circ} \mathrm{C}$ and $22^{\circ} \mathrm{C}$ are used as threshold temperatures, the present study finds that the summer (winter) has lengthened (shortened) about 14-15 d in the period 1961-2007, more than in the estimation of Dong et al. [15]. There are several possible reasons for such a discrepancy. (1) Different methods are applied to determine the timings of season beginnings, since the present study uses an adaptive filter to exclude interference from high-frequency fluctuations. (2) Different analysis periods are considered. The period 1951-2000 was con- 
sidered by Dong et al. [15], whereas the period 1961-2007, which has a larger warming trend than 1951-2000, is considered in the present study. (3) Homogenized data are used in the present study, having reduced the artificial trends at some sites to reflect better the large-scale climate change. Another discrepancy is that the advancing trend in early spring, especially in Rain Water, is the largest in the present study, whereas the advancing trend was larger in summer than in spring in the works of Dong et al. [15] and Yu et al. [16]. This discrepancy arises because Yu et al. [16] determined the spring (summer) onset by the timing of the five-day average temperature exceeding $10^{\circ} \mathrm{C}\left(22^{\circ} \mathrm{C}\right)$. According to the present study, the Summer Solstice (around $22^{\circ} \mathrm{C}$ ) has advanced more prominently than Pure Brightness (around $10^{\circ} \mathrm{C}$ ). However, the present study finds that there are timings (in early spring) that have advanced even more than that of the Summer Solstice. In particular, EEMD is employed in this study to exclude interference from highfrequency fluctuations, which cannot be satisfactorily excluded by the five-day running mean method [9], thus resulting in more robust results statistically.

The Waking of Insects, which has been considered the start of spring ploughing in central China ever since ancient times, is of great importance to agricultural activities. At this time, winter wheat in North China is in the stage of greening and soil is thawing; thus, timely smoothing out the surface of the soil is needed to reduce moisture evaporation. Meanwhile, to the south of the Yangtze River, wheat is jointing and rapeseed starts flowering, and timely top dressing is thus needed. In South China, peasants are sowing early paddy rice and carrying out measures to protect against the cold. Therefore, under the background of the Waking of Insects advancing everywhere in China, earlier execution of these agricultural activities is suggested to adapt to current climate change. In terms of temperature change, the smoothing out of the soil surface in North China's winter wheat area, top dressing to the south of Yangtze River, and the sowing of early paddy rice in South China may need to be carried out respectively $12-16,8-16$, and 4-12 d earlier in recent years than in the early 1960s.

Pure Brightness is also closely related to agricultural activities, as indicated by the peasant proverbs "Sowing beans and melons around Pure Brightness" and "Planting trees no later than Pure Brightness". Meanwhile, it is also the time for going on an outing in the spring. Thus, agricultural activities and spring travel related to this Solar Term on the North China Plain and in the Yangtze-Huaihe Basin may be planned several days earlier than in the early 1960s to adapt to the advancing trend in the timing of this climatic Solar Term in these areas.

Grain Full refers to the seeds of summer crops, such as winter wheat and barley, beginning to plumpen. At this time, peasants get ready for the summer harvest. In particular, in North China, dry and hot wind, with speed no less than 3-4 $\mathrm{m} / \mathrm{s}$, temperature exceeding $30^{\circ} \mathrm{C}$ and minimum relative humidity less than $30 \%$, is of great harm to winter wheat in the late growth stage and reduces production by $5 \%-10 \%$ or even $30 \%$. Therefore, under the background of earlier Grain Full in almost all semiarid zones of northern China, where aridification is severest [28,29], the summer harvest may need to be carried out earlier than usual (4-8 d earlier in recent years than in the 1960s). In southern China, the peasant proverbs for Grain Full indicate whether rain storage in a paddy rice field is sufficient. In addition, it is a time suitable for paddy rice planting in South China, where the timing of planting is closely related to the production amount per unit area. Therefore, under the background of earlier Grain Full almost everywhere in southern China, the planting of paddy rice in South China and storage of water in a rice field may need to be carried out earlier (4-8 d earlier in recent years than in the 1960s).

Grain in Ear is an important Solar Term for agricultural activities and directly affects production. At this time, winter wheat and barley have ripened and quick-harvesting is required in northern China. Meanwhile, it is also the time to sow summer crops. Under the background of significantly earlier Grain in Ear in almost all semi-arid zones in northern China, quick-harvesting in these areas may need to be carried out earlier (8-12 d earlier in recent years than in the 1960s). Meanwhile, midseason rice may need to be planted earlier in South China.

It should be mentioned that only a general method has been proposed in this study. Since China is a large territory, climate conditions and phenological characteristics in different regions, such as those in the mid-and lower reaches of the Yellow River and high-altitude freezing regions of the Tibetan Plateau, are quite different. Therefore, for any place of interest, a similar approach can be applied with local thresholds for Solar Terms according to the particular climate conditions and phenological characteristics. In addition, the discussions on the agricultural implications and adaptation strategies for changes in the Waking of Insects, Pure Brightness, Grain Full, and Grain in Ear are only in terms of temperature change. Other factors such as changes in precipitation and developments in modern agricultural technologies, especially seed-cultivation technology [3032], should also be taken into account to devise better adaptation strategies.

\section{Summary}

In this study, EEMD was applied to determine the temperature thresholds and the timings of the 24 climatic Solar Terms in China adaptively, using homogenized SAT datasets for the period 1960-2008. Trends in the timings and in the mean temperatures of the Solar Terms for the China mean were investigated. The geographic distributions of advancing or delaying trends in four phenology-related climatic Solar Terms were also investigated. The main conclu- 
sions are summarized as follows.

(1) In terms of the China mean, the number of cold days such as those of Slight Cold and Great Cold has decreased; in particular, there has been a $56.8 \%$ reduction in the number of cold days of Great Cold in the last 10 a (1998-2007; $14.0 \mathrm{~d} / \mathrm{a}$ ) relative to the number in the $1960 \mathrm{~s}$ ( $32.4 \mathrm{~d} / \mathrm{a})$. In 2007, all days were above the threshold temperature of Great Cold. Meanwhile, hot days like those of Great Heat have increased in number, by $81.4 \%$ in the last 10 years $(36.1 \mathrm{~d} / \mathrm{a})$ relative to the $1960 \mathrm{~s}(20.0 \mathrm{~d} / \mathrm{a})$. The timings of climatic Solar Terms during the warming period in the seasonal cycle have advanced significantly by more than $6 \mathrm{~d}$, especially $15 \mathrm{~d}$ for Rain Water, while those during the cooling period have delayed significantly by $5-6 \mathrm{~d}$.

(2) All Twenty-four Solar Terms for the China mean temperature have warmed significantly under global warming, resulting in a warm shift of the whole seasonal cycle. However, the warming trends for the warming part of the seasonal cycle are more prominent than those for the cooling part. The warming tendencies for Rain Water, the Beginning of Spring and the Waking of Insects are the largest for the period $1961-2007: 2.43^{\circ} \mathrm{C}, 2.37^{\circ} \mathrm{C}$ and $2.21^{\circ} \mathrm{C}$, respectively.

(3) Four phenology-related climatic Solar Terms, namely the Waking of Insects, Pure Brightness, Grain Full, and Grain in Ear, are found to have advanced almost everywhere. The advancing trend for climatic Insects Awaken is the most prominent, significant almost everywhere except in central China south of $33^{\circ} \mathrm{N}$. To the north of $33^{\circ} \mathrm{N}$, the trend in the east is larger than that in the west. For Pure Brightness, trends are significant everywhere except in the northwestern part of the Xinjiang Uygur Autonomous Region, Sichuan, eastern Yunnan, and some southeastern coastal areas. The geographic distributions of trends in the timing of Grain Full and Grain in Ear are much the same, with significant trends in many of the semiarid zones in northern China, the Yangtze-Huaihe valley, and southeastern coastal areas.

The implication of the present study for agriculture is that under the climate change of earlier timings of the Waking of Insects, Pure Brightness, Grain Full, and Grain in Ear almost everywhere in China, agricultural activities need to be brought forward by several days. It should be pointed out that besides temperature, other elements such as precipitation need to be taken into account in future work to better depict climatic Solar Terms and their changes.

The authors thank Prof. Ye Duzheng for introducing us to this work and for advice and discussions. We also thank two anonymous reviewers for their suggestions on improving the manuscript. This work was supported by the National Basic Research Program of China (2011CB952000 and 2009CB421401), the "Strategic Priority Research Program" of the Chinese Academy of Sciences (XDA05090100), and the National Natural Science Foundation of China (41005039 and 40810059003$)$.
1 IPCC. Climate Change 2007: The Physical Science Basis. Contribution of Working Group I to the Fourth Assessment Report of the Intergovernmental Panel on Climate Change. Cambridge and New York: Cambridge University Press, 2007. 996

2 Root T L. Effects of global climate change on North American birds and their communities. In: Biotic Interactions and Global Change. Sunderland, MA: Sinauer Associates, 1993

3 Crick H Q P, Sparks T H. Climate change related to egg-laying trends. Nature, 1999, 399: 423-424

4 Menzel A, Fabian P. Growing season extended in Europe. Nature, 1999, 397: 659

5 Zheng J Y, Ge Q S, Hao Z X. Climate change impacts on plant phenological changes in China in recent 40 years. Chin Sci Bull, 2002, 47: 1582-1587

6 Zheng J, Ge Q, Hao Z, et al. Spring phenophases in recent decades over Eastern China and its possible link to climate changes. Clim Change, 2006, 77: 449-462

7 Wang H J, Sun J Q. Variability of Northeast China river break-up date. Adv Atmos Sci, 2009, 26: 701-706

8 Qian C, Fu C, Wu Z, et al. On the secular change of spring onset at Stockholm. Geophys Res Lett, 2009, 36: L12706, doi: 10.1029/2009GL038617

9 Qian C, Fu C B, Wu Z, et al. The role of changes in the annual cycle in earlier onset of climatic spring in northern China. Adv Atmos Sci, 2011, 28: 284-296

10 Ren G Y, Guo J, Xu M Z, et al. Climate changes of China's mainland over the past half century (in Chinese). Acta Meteorol Sin, 2005, 63: 942-955

$11 \mathrm{Xu} \mathrm{M} \mathrm{Z,} \mathrm{Ren} \mathrm{G} \mathrm{Y.} \mathrm{Change} \mathrm{in} \mathrm{climatic} \mathrm{growth} \mathrm{period} \mathrm{over} \mathrm{China:}$ 1961-2000 (in Chinese). J Appl Meteorol Sci, 2004, 15: 306-312

12 Qian W H, Lin X. Regional trends in recent temperature indices in China. Clim Res, 2004, 27: 119-134

13 Song Y, Linderholm $\mathrm{H} \mathrm{W}$, Chen D, et al. Trends of the thermal growing season in China, 1951-2007. Int J Climatol, 2010, 30: 33-43

14 Zhai P, Pan X. Trends in temperature extremes during 1951-1999 in China. Geophys Res Lett, 2003, 30: 1913, doi:10.1029/2003GL018004

15 Dong W J, Jiang Y D, Yang S. Response of the starting dates and the lengths of seasons in Mainland China to global warming. Clim Change, 2010, 99: 81-91

16 Yu Z Y, Fan G Z, Hua W, et al. Variation characteristics of season start dates over China under the global warming (in Chinese). Clim Environ Res, 2010, 15: 73-82

17 Yan Z W, Xia J J, Qian C, et al. Changes in seasonal cycle and extremes in China during the period 1960-2008. Adv Atmos Sci, 2011, 28: 269-283

18 Wu Z, Huang N E. Ensemble empirical mode decomposition: A noiseassisted data analysis method. Adv Adapt Data Anal, 2009, 1: 1-41

19 Li Z, Yan Z W. Homogenized daily mean/maximum/minimum temperature series for China from 1960-2008. Atmos Ocean Sci Lett, 2009, 2: 237-243

20 Qian C, Yan Z W, Wu Z, et al. Trends in temperature extremes in association with weather-intraseasonal fluctuations in eastern China. Adv Atmos Sci, 2011, 28: 297-309

21 Huang N E, Shen Z, Long S R, et al. The empirical mode decomposition and the Hilbert spectrum for nonlinear and nonstationary time series analysis. Proc R Soc A-Math Phys Eng Sci, 1998, 454: 903-995

22 Huang N E, Wu Z. A review on Hilbert-Huang transform: Method and its applications to geophysical studies. Rev Geophys, 2008, 46: RG2006, doi:10.1029/2007RG000228

23 Qian C, Wu Z, Fu C B, et al. On multi-timescale variability of temperature in China in modulated annual cycle reference frame. Adv Atmos Sci, 2010, 27: 1169-1182

24 Qian C, Fu C, Wu Z. Changes in the amplitude of the temperature annual cycle in China and their implication for climate change research. J Clim, 2011, doi: 10.1175/JCLI-D-11-00006.1

25 Zhang B K. The duration of four seasons in China (in Chinese). Acta Geogr Sin, 1934, 1: 29-74

26 Jones P D, Briffa K R, Osborn T J, et al. Relationships between cir- 
culation strength and the variability of growing-season and coldseason climate in northern and central Europe. Holocene, 2002, 12: 643-656

27 Li J, Yu R, Zhou T, et al. Why is there an early spring cooling shift downstream of the Tibetan Plateau? J Clim, 2005, 18: 4460-4468

28 Fu C B, An Z S. Study of aridification in northern China-A global change issue facing directly the demand of nation (in Chinese). Earth Sci Front, 2002, 9: 271-275

29 Ma Z G, Fu C B. Some evidence of drying trend over northern China from 1951 to 2004. Chin Sci Bull, 2006, 51: 2913-2925

30 National Agricultural Technology Service Center. Introduction of the seeds approved on the Second Meeting of the Second National Crop Variety Approval Committee (V)—soybean (2) and wheat (1) (in Chinese). Seed Sci Tech, 2009, 5: 47-51

31 National Agricultural Technology Service Center. Introduction of the seeds approved on the Second Meeting of the Second National Crop Variety Approval Committee (V)—wheat (2) (in Chinese). Seed Sci Tech, 2009, 6: 49-51

32 National Agricultural Technology Service Center. Introduction of the seeds approved on the Second Meeting of the Second National Crop Variety Approval Committee (V)—wheat (2) (in Chinese). Seed Sci Tech, 2010, 5: 45-52

Open Access This article is distributed under the terms of the Creative Commons Attribution License which permits any use, distribution, and reproduction in any medium, provided the original author(s) and source are credited. 